\title{
REPRESENTAÇÕES SOCIAIS DE TRABALHADORES DA ATENÇÃO BÁSICA À SAÚDE SOBRE PESSOAS LGBT
}

\author{
SOCIAL REPRESENTATIONS OF PRIMARY HEALTH CARE \\ WORKERS ABOUT LGBT PEOPLE
}

\begin{abstract}
Ana Luísa Remor da Silva (D) ${ }_{(0000-0002-7444-6625)^{1}}$, Mirelle Finkler iD) ${ }_{(0000-0001-5764-9183)^{1}}$, Rodrigo Otávio Moretti-Pires ${ }_{(0000-0002-6372-0000)^{1}}$
\end{abstract}

\author{
${ }^{1}$ Universidade Federal de Santa Catarina, Programa de Pós-Graduação em Saúde Coletiva, Florianópolis, \\ SC, Brasil, <analu.remor@gmail.com>
}

Resumo No Brasil, apesar dos avanços na garantia dos direitos humanos das pessoas Lésbicas, Gays, Bissexuais, Travestis e Transexuais, elas continuam em importante situação de vulneração. O objetivo desta pesquisa bioética foi compreender as representações sociais dos trabalhadores da Atenção Básica à Saúde sobre essas pessoas, partindo-se da premissa que podem atuar como barreiras de acesso às ações e serviços. Foram entrevistados 15 trabalhadores(as) da rede de Florianópolis/SC. Os dados coletados foram qualitativamente analisados à luz da Teoria das Representações Sociais, por meio da análise temática de conteúdo. Os resultados revelaram que as representações sociais dos trabalhadores estão fortemente ancoradas em morais religiosas e heterônomas, compreendendo as pessoas em questão a partir de uma ideia de promiscuidade, de risco a infecções sexualmente transmissíveis, de estereótipos, e entendendo sua sexualidade e identidade de gênero como incorretas, determinadas biologicamente ou, ainda, como antinaturais, sujeitas a uma questão de escolha pessoal. A sexualidade é uma dimensão da vida privada que não pode continuar refém do moralismo. As representações sociais precisam ser trabalhadas nos contextos da educação e do trabalho em saúde, a fim de ampliar o acesso da população em foco às ações e serviços, bem como a qualidade assistencial.

Palavras-Chave pessoas LGBT; representações sociais; serviços de saúde; ética; bioética.
Abstract In Brazil, despite the improvements in guaranteeing the human rights of Lesbians, Gays, Bissexuals, and Transsexuals, this population is still in a considerable situation of vulnerability. The goal of the present bioethics research was to understand the social representations of the Primary Health Care workers regarding these people, following the premise that these representations can act as obstacles for the access to actions and services. A total of 15 workers from the network of the city of Florianópolis, in the state of Santa Catarina, Brazil, were interviewed. The data collected were analyzed quantitatively based on the Social Representation Theory, through the thematic analysis of the content. The results showed that the social representations on the part of the workers are strongly founded on religious and heterenomous morals, and they understand the group in question based on an idea of promiscuity, risk of acquiring sexuallytransmitted infections, stereotypes, and they understand their sexuality and gender identity as incorrect, biologically determined or even unnatural, subject to personal choice. Sexuality is a dimension of private life that cannot remain subjected to moralism. Social representations must be dealt with in the contexts of education and work in health, in order to broaden the access of the people in question regarding actions and services, as well as quality care.

Keywords LGBT people; social representations; health services; ethics; bioethics. 


\section{Introdução}

As representações sociais (RS) são entendidas como fenômenos que, de forma geral, permitem-nos identificar a relação entre as pessoas e o mundo em que vivem, para assim adaptar-se, orientar-se, localizar-se física ou intelectualmente, reconhecer e solucionar problemas (Jodelet, 1989). Dão sentido a um determinado elemento para interpretá-lo e naturalizá-lo, fazendo com que o mundo seja visto da maneira que se acredita que ele é ou deveria ser (Moscovici, 1978). As RS familiarizam elementos até então desconhecidos por meio de dois processos: a ancoragem, que relaciona algo novo a um conhecimento prévio, e a objetivação, que atribui significado a uma ideia, trazendo um esquema do âmbito conceitual/intelectual para o material, tornando-o real e redefinindo a relação sujeito-objeto (Moscovici, 1978; 1981).

A existência de RS que desqualificam a homossexualidade e a visão cisheteronormativa acerca dos papéis de gênero favorecem a manifestação de atitudes homofóbicas e geram importantes prejuízos ao acesso e à qualidade da assistência à saúde das pessoas LGBT ${ }^{1}$ (Lacerda, Pereira e Camino, 2002; Pereira et al., 2013; 2011), assim como a sua saúde mental e qualidade de vida (Pinto e Moleiro, 2012). Ainda que a maior parte dos estudos já realizados abordem apenas as RS sobre a homossexualidade, sendo desconhecidas as RS de lésbicas, bissexuais, travestis e transexuais, é possível se supor que sejam semelhantes quanto à desqualificação e validação de atitudes LGBTfóbicas.

Segundo Pereira et al. (2013, p. 86) “o preconceito pode ser o mecanismo psicológico por meio do qual as RS sobre a natureza dos grupos sociais fomentam a discriminação contra esses grupos". Assim, RS baseadas nas crenças explicativas sobre a homossexualidade podem ser determinantes da discriminação que as pessoas homossexuais sofrem. Isto justificaria o combate às teorias e concepções do senso comum que promovem estas formas de desrespeito e violência, e a valorização das que contribuem para inclusão social (Pereira et al., 2013) e que questionam, inclusive, a 'naturalização' da heterossexualidade.

Um estudo com estudantes universitários que investigou as RS da homossexualidade e sua relação com o preconceito a partir de cinco modelos explicativos - a homossexualidade como uma questão moral (falta de caráter); como uma questão religiosa (pecado por luxúria); como uma questão psicológica (originada por traumas); como uma questão biológica (alterações hormonais, fisiológicas ou gestacionais); e como uma questão psicossocial concluiu que a maioria destes modelos contribui para a ancoragem social do preconceito e da discriminação de pessoas homossexuais por relacioná-la a uma patologia - biológica ou psicológica - ou ainda, à imoralidade (Lacerda, Pereira e Camino, 2002). Outro estudo corrobora estes resultados, alertando que qualquer tipo de intervenção para prevenção ou redução do preconceito deve ser realizada em relação ao tipo de crença associada à natureza da homossexualidade (Pereira et al., 2011). 
As RS evidenciadas de um grupo de estudantes concluintes do curso de enfermagem sobre travestis e transexuais foram baseadas em uma visão biologicista e patologizante, reduzindo a vivência trans à necessidade de cirurgia. Os resultados revelam ancoragens em preconceito e juízos negativos de valor, com conceituações deturpadas, originando muitas vezes em ações pouco acolhedoras e compreensivas por parte dos entrevistados. A pesquisa destaca ainda a falta de conhecimento da temática pelos estudantes e conclui haver profunda necessidade de estudo e discussão do assunto nos cursos de enfermagem, assim como na área da saúde em geral (Moreira e Gomes, 2013).

Garcia et al. (2016), pesquisando as RS da própria população LGBT sobre saúde, observaram concepções reducionistas, destacando-se a ausência de doença com ênfase nas infecções sexualmente transmissíveis (ISTs) e dificuldades no acesso a consultas médicas, relacionadas à marcante presença da heteronormatividade, do preconceito social e institucional. Tais resultados referendam a situação não apenas de vulnerabilidade, mas de vulneração deste grupo social pelo enfrentamento constante de diversos obstáculos aos seus direitos sociais, e instigam à reflexão acerca da saúde da população LGBT, principalmente em relação à qualidade da assistência em todos os níveis de atenção à saúde (Silva, Finkler e Moretti-Pires, 2018; Tesser Júnior e Kovaleski, 2018; Garcia et al., 2016; Santos et al., 2015; Mansh, Garcia e Lunn, 2015; Wahlert e Fiester, 2013; Sousa et al., 2014; Pinto e Moleiro, 2012; Snelgrove et al., 2012; Makadon, 2011; Mello et al., 2011). No campo da bioética - que seria apropriada para o desenvolvimento de tais reflexões, surpreende a quase inexistência de estudos que explorem questões sobre sexualidade e identidade de gênero (Silva e Finkler, 2016; Nelson, 2012; Wahlert e Fiester, 2012).

Dentre os múltiplos elementos que compõem as RS, encontram-se valores e crenças (Jodelet, 1993) que são particularmente relevantes ao objeto deste estudo, uma vez que são também componentes essenciais das diferentes morais presentes em sociedades plurais como as ocidentais. Na história da ética, as normas morais costumam ser divididas entre as de fundamentação teônoma, heterônoma e autônoma. Mas ética e religião - experiência moral e experiência religiosa - são dois sistemas sociais e duas dimensões da vida humana estruturalmente articulados, de forma que "a ética se abre à religião e toda religião implica uma ética" (Gracia, 2010, p. 146). O problema metaético consiste justamente em definir o sentido desta articulação.

Entende-se por 'teonomia' as doutrinas morais que consideram que as leis morais são oriundas de preceitos religiosos, em que se acredita que há reciprocidade entre ética e religião. Porém, trata-se de questão muito complexa, já que o termo assumiu diferentes sentidos no decorrer do tempo, dando origem a, pelo menos, três tipos de éticas teônomas: a teonomia teônoma ou religiosa; a teonomia teológica ou heterônoma, e a teonomia filosófica ou autônoma. Embora sejam todas teonomias, neste trabalho iremos nos referir 
diretamente a elas como morais religiosas, heterônomas e autônomas (Gracia, 2010), respectivamente.

Na teonomia religiosa, a divindade dita as normas morais de modo incondicional, sendo os mediadores sagrados os únicos capazes de interpretá-las. Ao longo da história, tais interpretações tornaram-se insuficientes, demandando interpretações racionais. Surgiu, então, a teologia, e assim, a teonomia teológica ou heterônoma, em que a lei divina é expressada pela lei natural e pela lei revelada, em que fé e razão, ou melhor, teonomia e heteronomia são complementares. Já as éticas autônomas são modernas e foram elaboradas por filósofos, principalmente teólogos - alguns católicos, outros judeus - que acreditavam ser compatível uma nova interpretação entre ética e religião. A teonomia autônoma assim se chama por fazer uma opção fundamental teônoma, e por considerar critérios racionais autônomos nas decisões morais. Mas Gracia (2010, p. 213) aponta que, mais do que de 'autonomia teônoma', dever-se-ia falar de "autonomia religada", fazendo menção ao conceito de 're-ligação' de Zubiri que tem caráter transcendental e que não pode ser simplesmente reduzido à "religião", pois a 're-ligación' é o fundamento da 'ob-ligación', ou seja, da obrigação moral.

$\mathrm{O}$ respeito (e não apenas a tolerância) às diferentes maneiras de se viver a sexualidade e a identidade de gênero está fundamentado em uma moralidade caracteristicamente autônoma. Porém, as morais de fundamentações teônomas e heterônomas também permeiam nossos juízos de valor (morais) e nossas decisões de dever (juízos éticos). Frente a esta pluralidade moral, uma análise bioética a partir de uma ética laica e cívica (Cortina, 2005) foi adotada neste estudo. Seu objetivo maior era compreender as barreiras e as brechas no acesso da população LGBT à Atenção Básica à Saúde (ABS). Para tanto, delineou-se um objetivo específico de compreender as RS dos trabalhadores desses serviços sobre as pessoas LGBT, na expectativa de que esta compreensão contribua com avanços nas estratégias de sensibilização e melhor preparo dos trabalhadores para a produção da saúde - uma temática pautada pela Agenda Nacional de Prioridades de Pesquisa em Saúde (Brasil, 2011) e particularmente relevante para a formulação de políticas públicas, campo em que surgiram recentemente algumas iniciativas de mudança.

Entre elas, o "Brasil sem homofobia - Programa de Combate à Violência e à Discriminação contra GLBT e de Promoção da Cidadania Homossexual", instituído em 2004, foi uma importante concretização de conquistas sociais, políticas e jurídicas, após anos de luta pelo respeito à diversidade (Brasil, 2004, p. 27). Mais recentemente, a Política Nacional de Saúde Integral de Lésbicas, Gays, Bissexuais, Travestis e Transexuais - PNSI LGBT (Brasil, 2013) foi direcionada pelas diretrizes presentes no "Brasil Sem Homofobia", representando um marco importante, não apenas pelo reconhecimento de situação de vulneração social dessa população, mas também das consequências da 
discriminação no processo saúde e doença, e da necessidade de visibilidade e atendimento às demandas destas pessoas por tanto tempo negligenciadas. Outra mudança significativa foi realizada pelo Conselho Federal de Psicologia que em 2014 iniciou campanha em prol da despatologização das transexualidades e travestilidades, e posteriormente criou resolução específica (Conselho Federal de Psicologia, 2018) para a atuação de psicólogos em relação às pessoas transexuais e travestis, garantindo práticas que eliminem a transfobia e o preconceito (Conselho Federal de Psicologia, 2018).

\section{Percurso metodológico}

Esta pesquisa de caráter qualitativo teve como cenário o município de Florianópolis, tendo sido realizada em dois Centros de Saúde (CSs) selecionados pela maior probabilidade de assistirem à população trans que concentra residência em áreas específicas da cidade, segundo dados verbalmente informados pela Associação em Defesa dos Direitos Humanos em Enfoque na Sexualidade - $\mathrm{ADEH}^{2}$.

Após aprovação do projeto de pesquisa pela Secretaria Municipal de Saúde de Florianópolis e pelo Comitê de Ética em Pesquisa com seres Humanos da Universidade Federal de Santa Catarina (n. 1694085, 09/2016), iniciou-se a coleta de dados, que ocorreu em outubro e novembro de 2016, sob condução da pesquisadora principal - psicóloga, e na época, mestranda em Programa de Pós-Graduação em Saúde Coletiva, sendo os resultados aqui apresentados parte de sua dissertação de mestrado ${ }^{3}$-, com orientação da segunda autora, financiado pelo Programa de Bolsas da Capes. Ao seu término, ambas as instituições, bem como os participantes que manifestaram interesse, receberam os resultados da pesquisa. Informamos também que não há conflitos de interesse associados.

Participaram trabalhadores e trabalhadoras com todos os diferentes níveis de escolaridade que compõem a equipe de Saúde da Família. O primeiro contato foi realizado com os coordenadores dos CSs, para quem foi pedida a indicação de outros participantes, de forma a incluir trabalhadores(as) de diferentes profissões, um ao menos em cada CS. Desta forma, os(as) entrevistados(as) foram das seguintes áreas: Auxiliares ou Técnicos de Enfermagem e/ou de Saúde Bucal (4), Odontologia (3), Enfermagem (3), Medicina (2), Agentes Comunitários de Saúde (2) e Auxiliar Técnico-Administrativo (1), totalizando, portanto, 15 participantes, com média de 8 anos de trabalho e 4 anos de atuação nos CSs selecionados.

Os(as) trabalhadores(as) - neste texto identificados por códigos para a preservação do sigilo de suas identidades - foram contatados, pessoalmente ou por telefone, para realizar o convite para participar da pesquisa e saber se teriam disponibilidade e interesse. Neste momento foram pontuadas as prin- 
cipais questões sobre a pesquisa e os cuidados éticos ensejados. Já a leitura do Termo de Consentimento Livre e Esclarecido na íntegra foi realizada pessoalmente no início das entrevistas, as quais foram realizadas tanto no ambiente de trabalho do(a) participante, quanto em outros locais escolhidos por eles(as).

As entrevistas foram gravadas em áudio, tendo por base um roteiro semiestruturado previamente construído. As perguntas levaram em consideração a técnica de substituição, no intuito de dar liberdade para o participante expressar representações 'não permitidas' pelo seu grupo, atribuindo sua responsabilidade ao outro, ou seja, expressando-se pelo outro e não por si mesmo (Abric, 2005). O tempo total das entrevistas foi de aproximadamente 6 horas e 20 minutos, sendo o tempo médio de, aproximadamente, 25 minutos.

As entrevistas foram finalizadas com base na observação do critério de repetição e suficiência dos dados. A pesquisadora principal realizou as transcrições e, posteriormente, a equipe de pesquisa analisou as entrevistas com o auxílio do software Atlas.ti®7.5.16, por meio da Análise Temática de Conteúdo, em três etapas: pré-análise, exploração do material e tratamento dos resultados obtidos e interpretação (Minayo, 2008). Durante a segunda etapa, emergiram 74 códigos, que foram tematicamente agrupados na terceira etapa da análise em quatro categorias: atitudes éticas dos trabalhadores, problemas éticos vivenciados, questões de organização, estrutura e formação, e representações sociais. Esta última categoria, que atua majoritariamente como um entrave ao acesso da população LGBT à ABS, é o objeto de análise no presente artigo.

Os resultados mostraram que a população LGBT é representada por meio (1) das concepções morais sobre as orientações sexuais e identidades de gênero; (2) de determinados comportamentos sexuais; (3) de características pessoais; e (4) de dificuldades que são atribuídas à vivência como pessoas LGBT.

\section{RS relacionadas às concepções morais das pessoas LGBT}

A maioria das concepções morais (e, portanto, dos juízos morais) que puderam ser constatados acerca das pessoas LGBT parece estar atrelada a morais religiosas e/ou heterônomas. As concepções fundamentadas em uma moral autônoma foram as menos compartilhadas. O juízo moral que se sobressaiu foi o de que tudo que não se enquadra na cisgeneridade e na heterossexualidade é entendido como 'algo incorreto', em função de um ordenamento divino para a divisão binária de gênero. Este juízo fundamenta-se, portanto, em uma moral religiosa, segundo a qual o homem e a mulher foram feitos um para o outro: "Por questões religiosas, eu não acharia uma coisa certa. Acho que homem nasceu pra ser homem, mulher pra ser mulher" (E11). Seria, portanto, a concepção de que ser LGBT é 'pecado', ainda que este conceito não tenha sido verbalizado pelos participantes da pesquisa. 
A fala de alguns participantes trouxe à tona outra RS sobre ser LGBT: de que seria 'algo intrínseco à pessoa', como se fosse algo determinado biologicamente, com uma origem orgânica e, portanto, a partir de uma predisposição natural. Tal concepção parece estar fundamentada em uma moral heterônoma: "não é escolha, já nascem com essa predisposição" (E9); "têm muitas questões biológicas por trás disso" (E11). Tais falas não revelam o juízo moral de seus emissores, mas algumas denotaram um juízo moral negativo, como se fosse errado por ser 'antinatural': “a gente não vai forçar uma coisa que é 'ah, é super natural', porque não é! É uma coisa assim que a gente tenta entender e aceitar, mas natural, não é!" (E9).

Outra concepção significativa foi a da orientação sexual e identidade de gênero como uma alternativa, uma opção dependente, portanto, de uma 'decisão pessoal'. Neste caso, as fundamentações morais parecem se sobrepor, pois, ao mesmo tempo em que há o julgamento de que seria errado, é compartilhada a ideia da possibilidade de escolha, parecendo fugir de uma concepção exclusivamente fundamentada em uma moral religiosa. Neste sentido, ao considerá-las incorretas, supõe-se que, além de uma fundamentação religiosa, haja também uma fundamentação heterônoma, pois se retoma a ideia de ir contra as normas 'naturais'. A referida possibilidade de escolha remete ainda a uma fundamentação autônoma, pois nem todos aqueles que entendem que ser LGBT é uma escolha pessoal necessariamente evidenciaram uma base moral religiosa: "se foi escolha daquela pessoa a gente tem mais é que respeitar" (E2); "acho que não é uma coisa correta. Mas eu entendo que são pessoas que têm uma opção e assim por diante, elas são livres pra isso assim"(E13).

Também esteve presente, ainda que sutilmente, certa crítica às concepções anteriores que são hegemônicas, sugerindo uma possível fundamentação moral autônoma, quando se percebeu a compreensão do ser humano para além de suas crenças religiosas e sem procurar uma justificativa baseada em questões biológicas: “a gente tem essa cultura - homem, branco, hetero cis - que dá isso (ser LGBT) como se fosse uma anormalidade (...) fico pensando uma mulher trans, negra e pobre, o que que ela deve passar, como deve ser a vida dela? (...) deve ser muito sofrida. E com certeza ela não tá ali por frescura (...) é porque ela é assim..."(E14). Contudo, a coleta de dados realizada não foi suficiente para trazer elementos que pudessem confirmar esta percepção. De todo modo, a ausência (ou quase ausência) de uma concepção moral sobre as orientações sexuais e sobre as identidades de gênero como construções sociais, inclusive sobre a heterossexualidade e a cisgeneridade, a partir de uma moral autônoma, não deixa de ser um dos resultados mais relevantes.

No Quadro 1, apresentam-se as diferentes RS relacionadas à concepção moral das pessoas LGBT, de acordo com cada uma das diferentes fundamentações morais. 
Quadro 1

Representações Sociais de trabalhadores da ABS relacionadas à concepção moral sobre pessoas LGBT.

\begin{tabular}{|ll|}
\hline Representações Sociais relacionadas à concepção moral sobre pessoas LGBT & Fundamentação \\
\hline Ser LGBT é pecado, porque vai contra os ensinamentos divinos/religiosos. & Religiosa \\
Ser LGBT é algo intrínseco, porque simplesmente vem com a pessoa. & Heterônoma \\
Ser LGBT é antinatural. & \\
Ser LGBT é uma decisão pessoal. & Autônoma \\
Ser LGBT é uma construção social. & \\
\hline
\end{tabular}

Ser LGBT é uma construção social.

Fonte: os autores.

\section{RS relacionadas a comportamentos sexuais das pessoas LGBT}

As RS relacionadas a comportamentos sexuais dizem respeito à forma com que os trabalhadores entendem que as pessoas LGBT lidam com sua vida sexual, principalmente em relação à homossexualidade, tanto em relação à quantidade de parceiros, como em relação à prevenção e cuidados pessoais. O que se pode perceber é uma forte associação com 'infecções sexualmente transmissíveis (IST)', estando, em menor grau, também associadas questões de 'promiscuidade e comportamentos de risco': “um homossexual, por exemplo, que tem relação com outro homem, desprotegida, normalmente vai pedir uns exames" (E1); "os gays ainda vêm mais, procuram mais, geralmente por causa das DSTs" [doenças sexualmente transmissíveis] (E11); "muitos, não todos, tem uma vida promíscua né?" (E9).

\section{RS relacionadas a características das pessoas LGBT}

As representações sociais das pessoas LGBT vinculadas a características pessoais, tanto físicas como comportamentais, apresentaram conteúdos estereotipados, como o do homem gay com características afeminadas e a da mulher lésbica com características masculinizadas. Ainda que reconheçam que a aparência não é suficiente para identificar a sexualidade da pessoa, os trabalhadores se orientam principalmente pela 'aparência física e pela linguagem gestual dos usuários': "modo de agir e de falar, às vezes é 'ai', vira a mão, gesticula, sabe? Fala e, às vezes, jeito de andar, roupa, se vestir" (E2); “A gente já imagina uma pessoa né, que se veste mais masculina ou que se comporta de um jeito mais masculino, a gente... já dá um clickzinho: 'acredito essa pessoa tem essa opção sexual'. Porque já é automático, assim como um homem também. Alguns homens, apesar de ter a opção sexual por outros homens, não têm nenhum comportamento diferenciado, outros têm. Têm uma voz mais afeminada ou se vestem de uma forma diferenciada, mais afeminado" (E6); "ainda a gente tem isso exposto na imprensa, na mídia, programa de televisão, que associa um homem mais delicado que tem trejeito 
de homossexual" (E5). Cabe ressaltar a pouca visibilidade das pessoas trans e travestis nesta categoria de análise.

Outros elementos que participam da representação social das pessoas LGBT relacionadas às características pessoais são a ideia de serem pessoas 'extrovertidas', e sob o ponto de vista de alguns participantes, 'corajosas': “eu acho gay muito divertido, então, eu posso associar a essa palavra (alegria) né? [risos], quando tu vê gay tu já imagina, tipo... eu tenho amigos gays, assim, e tu já imagina até uma alegria” (E4); “coragem porque as pessoas que se identificam como LGBT vão enfrentar muitos desafios, né? Só uma pessoa corajosa que assume esse tipo de desafio" (E5); "a coragem em expor isso (gênero e sexualidade) pra sociedade, se ela quiser realmente ter uma vida feliz e ser verdadeira consigo mesma, ela vai ter que ter coragem de expor isso" (E6).

\section{RS relacionadas a dificuldades vivenciadas por pessoas LGBT}

Algumas dificuldades atribuídas à vivência LGBT compõem a representação social de que há diversos 'obstáculos' sociais quando alguém se identifica como homossexual ou transexual. Tal perspectiva abrange a ideia de que as pessoas LGBT geralmente passam ou vão passar por algum tipo de 'violência e sofrimento', por serem mal compreendidas, por sofrerem preconceito e por serem 'marginalizadas e excluídas', uma vez que vão contra padrões sociais e morais, em especial, as pessoas trans e travestis: "[suspiro] quê que eu penso? São pessoas como outra qualquer, só que eu fico com um pouco de... por exemplo, eu sei que pena não é uma palavra boa, mas eu fico com... assim... é... achando que a pessoa vai sofrer, por ter que passar por tudo isso, sabe?' (E6); “rejeitados porque eles não conseguem nem muitas vezes um atendimento médico, hospitalar, trabalho, pelas pessoas acharem que eles são fora da sociedade, excluídos mesmo" (E7); "pra grande parte da população é uma população que fica à margem, que fica deslocada, isolada e que eles tentam se inserir, mas muitas vezes não é permitido" (E8).

Há também a representação social de que muitos LGBT podem estar em "conflito psicológico" em relação à sua sexualidade e identidade de gênero: “ah tem gente que precisa de uma... mais uma coisa psicológica, porque tá nessa coisa do não sabe ou não tá entendendo consigo" (E3); “algumas situações de que vêm à procura de uma... de atendimento psico... psicológico, psiquiátrico, porque recentemente se identificaram gostando de pessoas do mesmo sexo, então isso pode tá por trás também assim, que é uma descoberta recente" (E13).

Uma minoria aponta para os 'direitos reduzidos' da população LGBT: “eu acho que tem que ter o mesmo direito, mesma liberdade que os héteros têm" (E14). A mídia em geral, destacadamente a alternativa, foi considerada um 
meio que permite maior visibilidade às causas LGBT, evidenciando as violências sofridas por esta população: "na sociedade como um todo, o movimento LGBT se unindo, crescendo. As mídias alternativas, a rede social tem feito isso" (E14). Ainda assim, houve também o reconhecimento da mídia como um reforçador de estereótipo.

O Quadro 2 expõe uma síntese dos principais resultados.

Quadro 2

Representações sociais de trabalhadores da ABS sobre as pessoas LGBT.

\begin{tabular}{|ll|}
\hline $\begin{array}{l}\text { Representações sociais das } \\
\text { pessoas LGBT relacionadas a... }\end{array}$ & Conteúdo das representações sociais \\
\hline ... concepções morais & $\begin{array}{l}\text { As orientações sexuais e identidades de gênero que divergem da cis-heteronorma } \\
\text { são compreendidas como comportamentos pecaminosos ou incorretos, porque são } \\
\text { contrários à ordem divina ou natural ou porque é algo intrínseco, da natureza das } \\
\text { pessoas, ou ainda, são fruto de uma decisão pessoal. }\end{array}$ \\
As pessoas LGBT fazem parte de uma população mais propensa a riscos de doenças \\
e infecções sexualmente transmissíveis, com um comportamento sexual promíscuo \\
e de risco. \\
A... características pessoais & $\begin{array}{l}\text { As pessoas LGBT são extrovertidas e reconhecíveis por meio de características } \\
\text { afeminadas ou masculinizadas. }\end{array}$ \\
A... dificuldades vivenciadas & As pessoas LGBT enfrentam diversos obstáculos sociais e sofrem situações de \\
& violência, exclusão, marginalização, e ainda, conflitos psicológicos.
\end{tabular}

Fonte: os autores.

\title{
Fundamentos e implicações das RS desveladas
}

\begin{abstract}
...fundamentar é argumentar, oferecer razões bem articuladas para esclarecer por que preferimos alguns valores e não outros, certas teorias e não outras, determinados critérios e não outros. Ao mostrar os fundamentos que nos ajudam a manter o que cremos, fugimos da arbitrariedade e prevenimos o fanatismo próprio da crença cega e da adesão incondicional (Cortina e Martínez, 2005, p. 127).
\end{abstract}

Fundamentar eticamente é refletir sobre as diversas morais que caracterizam a pluralidade de nossa sociedade e que influenciam nossos comportamentos e ações. A situação de vulneração a que estão submetidas as pessoas LGBT e, particularmente, alguns subgrupos como o de pessoas transexuais e travestis, evidencia o quão improrrogável é a sensibilização para uma mudança atitudinal coletiva. Daí a importância de se compreender a origem dos juízos morais relacionados à temática da diversidade sexual e da identidade de gênero.

Na fundamentação moral religiosa, Deus "é o fundamento direto da norma" (Gracia, 2010, p. 180). Julga-se, então, que a cisgeneridade e a heterossexu- 
alidade seriam vontades divinas e que, portanto, as pessoas LGBT estariam descumprindo uma determinação sagrada. Os resultados que sugerem a ancoragem das RS nesta moral parecem objetificar todas as formas que subvertem a cis-heteronorma em pecado, o que pode sustentar atitudes discriminatórias em diferentes âmbitos, mesmo sem a percepção consciente das pessoas que as concebem e praticam.

Já as RS ancoradas em uma moral heterônoma indicam que as questões de gênero e sexualidade seriam intrínsecas às pessoas. Uma concepção que remete à visão biomédica da homossexualidade, herança de uma história de patologização ainda fortemente presente em relação à transexualidade. Esta RS parece ser objetificada pela natureza, tanto no sentido de ser algo natural (biologicamente determinado), como no sentido de ser antinatural, daí podendo compreender-se a aparente ausência de juízo de valor ou, quando presente, um juízo negativo. Tal concepção pode também dificultar a compreensão e empatia dos trabalhadores em relação às pessoas LGBT (Scardua e Souza Filho, 2006).

Ao longo da história, a percepção da homossexualidade, principalmente com a apropriação do termo pela medicina, foi construída como anormalidade a partir de juízos morais e outros mecanismos de regulação social. A sua patologização, seja pela compreensão biológica ou psicológica, deu-se principalmente por uma inversão do objeto de estudo, pois o que determinou como anormal a homossexualidade não foi a ciência, mas o poder legitimado pela moral hegemônica da época (Martins et al., 2014). Em especial as pessoas trans e travestis sofreram e ainda sofrem exclusão social, com justificativas atreladas a sua patologização, pois ainda é corrente a concepção de ser 'antinatural' ir contra o gênero designado ao nascimento em função do sexo biológico (Jesus, 2012).

Ao se reconhecer que as relações sociais do sujeito com o seu corpo, com as outras pessoas, e com a sociedade como um todo são influenciadas e mediadas por diferentes esferas - linguagem, crenças, tradições, cultura, valores - uma perspectiva naturalista se torna insuficiente para se pensar em saúde, porque

a saúde é marcada num corpo que é simbólico, onde está inscrita uma regulação cultural sobre o prazer e a dor, bem como ideais estéticos e religiosos. Destacando assim, nas diversas sociedades, o corpo simbólico, as representações da vida e da morte, do normal e do anormal, as práticas sanitárias não podem silenciar sobre o tecido social, marcado pelas diferenças. O reconhecimento do caráter simbólico do corpo impede sua representação como apenas uma máquina anátomo funcional, constituída por mecanismos bioquímicos e imunológicos (Birman, 2005, p.13).

É necessário, portanto, o reconhecimento dos corpos, gêneros e sexualidades dissonantes da cisgeneridade e da heterossexualidade como manifestações 
humanas legítimas e não como questões que fogem à norma. Também a desvinculação da concepção de sexualidade para fins reprodutivos é essencial para democratização dos direitos sexuais, reprodutivos, de exercício à autonomia. Desta forma, é imprescindível repensar nos direitos sexuais e reprodutivos, quebrando paradigmas a respeito das normatizações da sexualidade que se baseiam na lógica hetero cisnormativa. Tal processo implica na legitimação de diferentes discursos a respeito da sexualidade, e ainda no seu reconhecimento como instrumento crítico ao saber biomédico. Assim seria possível a efetivação de um Sistema Único de Saúde que garanta os direitos de cidadania relativos ao campo da saúde integral para a população LGBT (Lionço, 2008).

As RS das pessoas LGBT constituídas por concepções morais da homossexualidade, fundamentadas principalmente nas morais religiosas e heterônomas, também foram evidenciadas em pesquisas com diferentes grupos de participantes, referendando o preconceito socialmente compartilhado (Moreira e Gomes, 2013; Pereira et al., 2013; 2011; Lacerda, Pereira e Camino, 2002).

Foi possível também identificar uma comunicação entre as fundamentações morais religiosas e heterônomas, no sentido de se retroalimentarem. De fato, as diferentes fundamentações morais são complementares (Gracia, 2010). As concepções de que ser LGBT é pecado ou que seja um fato antinatural se aproximam ao fugirem das normas morais, sejam elas de origem divina ou da natureza, reforçando a heteronormatividade e, consequentemente, a LGBTfobia. Ao mesmo tempo, diferem-se quanto à responsabilização das consequências, pois, partindo-se de morais religiosas, parece haver uma maior culpabilização pessoal. Neste mesmo sentido, Borrillo (2001) aponta que a crença em uma suposta vinculação da homossexualidade a uma herança genética contribui para uma maior tolerância das pessoas. Por outro lado, há que se lembrar de que o conceito de natural foi frequentemente interpretado no sentido estático para justificar supremacias injustas como as promovidas pelo nazismo (Berlinguer, 1993). Por conta disto, bioéticas mais críticas apontam justamente para a importância da análise ética laica, de forma a se buscar a argumentação e reflexão daqueles que se apoiam em morais com forte herança religiosa, biomédica e patriarcal (Silva e Finkler, 2016; Diniz e Guilhem 2009; Berlinguer, 2004).

A cis-heteronormatividade e a LGBTfobia são fortes pilares sustentados pelo machismo, que é estrutural e estruturante da nossa sociedade. Borrillo (2001) compreende que o sexismo, além de subordinar o feminino ao masculino, igualmente hierarquiza as sexualidades, sendo este um fundamento da homofobia. O reforço constante de superioridade moral e biológica da heterossexualidade, ou seja, da heteronormatividade, é "uma estratégia política de construção da normalidade sexual. A heterossexualidade aparece, assim, como o padrão com o qual todas as outras sexualidades devem ser comparadas e medidas" (Borrillo, 2001, p. 25). 
As RS que atrelam orientação sexual e identidade de gênero a uma decisão pessoal indicam uma fundamentação autônoma. Esta concepção esteve presente também nas RS de estudantes heterossexuais universitários do Rio de Janeiro, ao contrário dos estudantes homossexuais que apontavam a não intencionalidade da homossexualidade (Scardua e Souza Filho, 2006). É possível compreender que tal concepção possa justificar a responsabilização e a culpabilização das pessoas homossexuais em relação à sua orientação sexual, validando atitudes de preconceito e discriminação (Santos, Shimizu e Merchan-Hamann, 2014; Scardua e Souza Filho, 2006).

A RS da homossexualidade e da transexualidade como decisão pessoal está baseada em uma concepção ultrapassada do ponto de vista de diversas correntes teóricas, ao ponto da terminologia atual empregar o termo 'orientação sexual' e não mais 'opção sexual'. A orientação sexual e a identidade de gênero são construções sociais (Jesus, 2012; Butler, 2003) da mesma forma que a cisgeneridade e a heterossexualidade, e jamais devem ser desvalidadas (Jesus, 2012). A mudança para esta concepção poderia ser um primeiro passo para a diminuição do preconceito e da discriminação (Pereira et al., 2011).

Compreender a sexualidade humana como uma dimensão da vida sem (de) limitá-la por juízos morais como certo ou errado, natural ou não natural, é questão de uma ética de mínimos ou de uma ética de justiça (Cortina e Martínez, 2005). Sobretudo trabalhadores de saúde deveriam compreender gênero e sexualidade para além de corpos inteligíveis e, consequentemente, de uma visão binária. A inteligibilidade é um processo socialmente imposto e instituído, colocando como 'proibidas de existir' quaisquer identidades de gênero que destoem da norma sociocultural (Butler, 2003). Portanto, é importante compreender que gênero e sexualidade são fenômenos complexos e que o pluralismo moral implica em se compartilhar certos mínimos de justiça, segundo os quais se concorda em possibilitar que cada um viva segundo seu modelo de felicidade - uma ética de máximos - e possa convidar os demais a seguir seu modo de vida, sem nunca impô-lo. Esta deveria ser a perspectiva de um Estado laico e democrático, que implica no respeito aos direitos humanos e à diversidade de comportamentos e ideias, e na busca de objetivos comuns: os mínimos de justiça, a todos (Cortina e Martínez, 2005; Berlinguer, 2004).

A relação histórica de IST com pessoas LGBT reforça preconceitos e estigmas, dificultando inclusive que assumam sua identidade por medo de discriminação (Rodriguez, 2014). A sexualidade do homem gay, por apresentar comportamentos que contradizem o esperado pela heteronormatividade, "é entendida como ilícita, promíscua, ameaçadora e não salutar, uma vez que está fora das margens de legitimação familiar" (Moscheta, Fébole e Anzolin, 2016, p. 77). Sociedades que têm a heterossexualidade como modelo tomam qualquer orientação fora deste padrão como imoral. Assim, homens homossexuais acabam sendo retratados como frívolos e promíscuos; e mulheres homos- 
sexuais, como hostis e agressivas aos homens (Borrillo, 2001), características que reforçam a RS de que seriam mulheres masculinizadas.

O padrão comportamental encontrado na RS das pessoas LGBT, de comportamentos afeminados em homens gays e masculinizados em mulheres lésbicas, influenciam nos atendimentos à população LGBT, pois os trabalhadores costumam se orientar por estas características, o que pode ser, inclusive, um gatilho para o preconceito. A associação da mulher cis lésbica com a masculinidade reflete estereótipos que podem colaborar com o estado de vulneração dessas mulheres, principalmente em relação à saúde, como demonstrado na literatura (Carvalho, Calderaro e Souza, 2013; Barbosa e Facchini, 2009). Este elemento das RS é constantemente veiculado na mídia em geral de forma estereotipada, porém vem apresentando pequenas mudanças ao longo do tempo (Baggio, 2013), pois algumas mídias alternativas procuram desconstruir tais estereótipos, colocando em foco a luta pelos direitos da população LGBT.

Cabe ainda destacar o pouco conhecimento dos participantes deste estudo em relação à transexualidade e o equívoco entre identidade de gênero e orientação sexual como também observado em outro estudo (Moreira e Gomes, 2013), tendo sido difícil compreender a RS das pessoas trans e travestis para este grupo. Mas há também que se considerar a possibilidade da transexualidade não se constituir objeto de representação social no grupo estudado, pela simples falta de compreensão da temática (Santos, Shimizu e Merchan-Hamann, 2014). De qualquer forma, foi evidente a invisibilidade social das pessoas trans e travestis, o que permite compreender o preconceito por elas enfrentado nos serviços de saúde (Rodriguez, 2014). Ainda há que se comentar que as pessoas bissexuais nem foram lembradas pelos participantes desta pesquisa.

A RS de que as pessoas LGBT vivenciam diversas dificuldades, como obstáculos sociais, violência, sofrimento e exclusão social, pode ser interpretada como uma brecha no acesso da população LGBT à ABS apenas se considerarmos a sensibilidade e a empatia dos trabalhadores na busca de ações promotoras de equidade. Possivelmente ancorada a esta representação, encontra-se ainda, porém menos presente, outro elemento, também observado no estudo de RS com profissionais de saúde sobre transexualidade (Santos, Shimizu e Merchan-Hamann, 2014): o de que seriam pessoas corajosas em função de tais vivências. Uma representação ancorada na necessária e incessante luta por direitos básicos, principalmente para as pessoas trans e travestis, inclusive em relação à própria identidade (Jesus, 2012). As pessoas LGBT vivenciam forte hostilidade em relação a sua sexualidade, derivada de uma agressividade despertada por julgamentos morais. Até mesmo a compaixão pode ser entendida como desencadeadora de insatisfação com a própria sexualidade e de sofrimento psíquico por ansiedade, depressão, vergonha etc. (Borrillo, 2001). Mas os participantes desta pesquisa que compartilham da RS de que as 
pessoas LGBT enfrentam conflitos psicológicos associam tais conflitos majoritariamente à (homo)sexualidade e não às vivências de repressão e violências. Relacionam, portanto, a sexualidade divergente a um 'desequilíbrio', seja do ponto de vista emocional ou moral.

\section{Considerações finais}

Com relação às limitações da pesquisa, aponta-se o fato de que nem todos os trabalhadores conheciam o significado de todas as letras que compõem a sigla LGBT, de modo que se pode ter perdido certas peculiaridades em relação às diferentes sexualidades e identidades de gênero representadas pela sigla que interferissem nas RS, ou ainda, tal desconhecimento pode ter contribuído para o pouco aprofundamento das respostas de alguns trabalhadores. De toda forma, suas falas - quase que exclusivamente referentes à homossexualidade - refletem a pouca visibilidade e reconhecimento das especificidades de atendimento de lésbicas, bissexuais, travestis e transexuais.

A modo de conclusão, salienta-se que a compreensão das RS dos trabalhadores a respeito das pessoas LGBT foi essencial para identificar as questões éticas que permeiam sua assistência à saúde, validando os pressupostos de uma forte fundamentação religiosa e heterônoma na moral hegemônica, reforçadoras do preconceito relacionado às pessoas LGBT. São fundamentações morais que se sobrepõem, ocorrendo de forma articulada e, às vezes, ambivalente. Acabam por assumir diferentes papéis dentro do contexto da ABS, mas principalmente de entraves que, ao mesmo tempo, banalizam a discriminação e a LGBTfobia. Trata-se de um cenário coeso, visto que o machismo, a heteronormatividade, a visão binária de gênero, a cisnormatividade e a LGBTfobia permeiam, em diferentes níveis, as RS observadas.

Assim, pode-se afirmar que as RS que desqualificam as pessoas LGBT com uma ideia de promiscuidade, risco à IST, e outros estereótipos, entendendo sua sexualidade e identidade de gênero como pecaminosas, incorretas, determinadas biologicamente ou antinaturais, ou ainda, sujeitas a uma escolha pessoal, operam como barreiras no acesso às ações e serviços da ABS, prejudicando a qualidade da atenção à saúde desta população.

Ainda assim, vislumbram-se perspectivas de mudança por meio de atitudes éticas e de RS positivas que podem contribuir na sensibilização e melhoria dos atendimentos às pessoas LGBT, tais como a disponibilidade dos trabalhadores em fazer o seu melhor e em se preocupar com a qualidade do atendimento, ou a RS de que as pessoas LGBT vivem situações de dificuldades e preconceitos nas relações sociais. Faz-se necessário o reconhecimento de tais situações também nas unidades de saúde, assumindo-se assim a responsabilidade pela transformação das práticas. A disponibilidade pessoal para a autocrítica e para a reflexão sobre o trabalho em saúde e em equipe precisa ser estimulada 
diariamente, a fim de que ações discriminatórias não permaneçam despercebidas, mas sim, passem a ser pauta de enfrentamento no cotidiano das equipes.

A sexualidade é uma dimensão da vida privada que não pode continuar refém do moralismo. As questões de gênero e sexualidade são fenômenos complexos, para muito além da dominante visão binária de gênero. Tais concepções precisam ser trabalhadas na sociedade como um todo e especialmente nos contextos da educação e do trabalho em saúde. É importante reconhecer esta demanda como um significativo desafio para as políticas públicas, políticas estas que somente são possíveis por meio da democratização do Estado brasileiro, do compartilhamento de uma ética cívica, laica, que permita alcançarmos coletivamente mínimos de justiça, sem os quais os máximos de felicidade não poderão ser buscados por cada um de seus cidadãos.

\section{Colaboradores}

Ana Luisa Remor da Silva realizou todas as etapas da pesquisa e a redação do artigo. Mirelle Finkler participou da concepção e delineamento da pesquisa, da análise dos dados, da redação do artigo e da aprovação da sua versão final. Rodrigo Otávio Moretti-Pires contribuiu no delineamento da pesquisa, na discussão dos resultados, na redação do artigo e na aprovação da sua versão final.

\section{Financiamento}

O presente trabalho foi realizado com apoio da Coordenação de Aperfeiçoamento de Pessoal de Nível Superior - Brasil (CAPES) - Código de Financiamento 001. 


\section{REPRESENTACIONES SOCIALES DE LOS TRABAJADORES DE LA ATENCIÓN BÁSICA DE LA SALUD SOBRE LAS PERSONAS LGBT}

Resumen En Brasil, a pesar de los avances para garantizar los derechos humanos de las personas Lesbianas, Gais, Bisexuales, Travestis y Transexuales, éstas continúan en una importante situación de vulnerabilidad. El objetivo de esta investigación bioética fue comprender las representaciones sociales creadas por los trabajadores de la Atención Básica de la Salud sobre estas personas, partiendo de la premisa que dichas representaciones pueden actuar como barreras de acceso a las acciones y servicios. Se entrevistaron 15 trabajadores(as) de la red de la ciudad de Florianópolis, Brasil. Los datos recolectados se analizaron cualitativamente a la luz de la Teoría de las Representaciones Sociales, por medio del análisis de contenido temático. Los resultados revelaron que las representaciones sociales de los trabajadores están fuertemente arraigadas a las morales religiosas y heterónomas, percibiendo a las personas en cuestión a partir de una idea de promiscuidad, de riesgo a infecciones sexualmente transmisibles, de estereotipos, y concibiendo como incorrectas su sexualidad e identidad de género establecidas biológicamente, o incluso como antinaturales, sujetas a una cuestión de elección personal. La sexualidad es una dimensión de la vida privada que no puede continuar siendo rehén del moralismo. Las representaciones sociales deben trabajarse en los contextos de la educación y del trabajo en la salud a fin de ampliar el acceso de la población a las acciones y servicios, poniendo el foco en esto así como en la calidad asistencial.

Palabras clave personas LGBT; representaciones sociales; servicios de salud; ética; bioética.

\section{Notas}

${ }^{1}$ Optou-se por utilizar a sigla LGBT (Lésbicas, Gays, Bissexuais, Travestis e Transexuais) neste artigo de acordo com a deliberação pelo movimento na Conferência Nacional de Gays, Lésbicas, Bissexuais, Travestis e Transexuais realizada em 2008 (BRASIL, 2013). Reconhecemos a limitação da sigla e valorizamos a necessidade de destaque e reconhecimento das diversidades que não são diretamente representadas por ela, sendo esta uma intensa e necessária discussão nos movimentos sociais.

${ }^{2}$ Associação de grande importância no município, sendo referência também no estado, de apoio jurídico e psicológico dentre diversas outras ações, todas gratuitas, que também priorizam a saúde da população LGBT.

${ }^{3}$ SILVA, Ana L.R. Atenção Básica à Saúde da População LGBT: uma análise bioética a partir das representações sociais de trabalhadores da saúde. 149p. Dissertação (Mestrado) - Universidade Federal de Santa Catarina, Centro de Ciências da Saúde, Programa de Pós-Graduação em Saúde Coletiva, Florianópolis, 2017. 


\section{Referências}

ABRIC, Jean C. A zona muda das representações sociais. In: OLIVEIRA, Denise C.; CAMPOS, Pedro H. F. (org.). Representações sociais: uma teoria sem fronteiras. Rio de Janeiro: Museu da República, 2005. p. 23-34.

BAGGIO, Adriana T. A temática homossexual na publicidade de massa para público gay e nãogay: conflito entre representação e estereótipo. Revista UNINTER de Comunicação, Curitiba, v. 1, n. 1, p. 100-117, 2013. Disponível em: <goo.gl/Ujfd2D >. Acesso em: 21 dez. 2018.

BARBOSA, Regina M.; FACCHINI, Regina. Acesso a cuidados relativos à saúde sexual entre mulheres que fazem sexo com mulheres em São Paulo, Brasil. Cadernos de Saúde Pública, Rio de Janeiro, v. 25, supl. 2, p. s291-s300, 2009. Disponível em: < goo.gl/G4P94n > Acesso em: 21 dez. 2018.

BERLINGUER, Giovanni. Bioética Cotidiana. Brasília: Universidade de Brasília, 2004.

BERLINGUER, Giovanni. Questões de vida: ética, ciência, saúde. São Paulo: Hucitec; Londrina: APCE; Salvador: CEBES, 1993.

BIRMAN, Joel. A physis da saúde coletiva. Physis: Rev. Saúde Coletiva, Rio de Janeiro, v. 15, p. 11-16, 2005. Disponível em: <goo. gl/VPc3h7> . Acesso em: 21 dez. 2018.

BORRILLO, Daniel. Homofobia. Barcelona: Bellaterra, 2001.

BRASIL. Ministério da Saúde. Secretaria de Gestão Estratégica e Participativa. Departamento de Apoio à Gestão Participativa. Politica Nacional de Saúde Integral de Lésbicas, Gays, Bissexuais, Travestis e Transexuais. 1. ed. Brasília: Ministério da Saúde, 2013. 32 p.

BRASIL. Ministério da Saúde. Secretaria de Ciência, Tecnologia e Insumos Estratégicos. Departamento de Ciência e Tecnologia. Agenda nacional de prioridades de pesquisa em saúde.
2. ed. Brasília: Ministério da Saúde, 2011. 68

p. (Série B. Textos Básicos em Saúde).

BRASIL. Ministério da Saúde. Conselho Nacional de Combate à Discriminação. Brasil Sem Homofobia: programa de combate à violência e à discriminação contra GLTB e promoção da cidadania homossexual. Brasília: Ministério da Saúde, 2004. 32 p.

BUTLER, Judith. Problemas de gênero: feminismo e subversão da identidade. Rio de Janeiro: Civilização Brasileira, 2003.

CARVALHO, Cintia S.; CALDERARO, Fernanda; SOUZA, Solange J. O dispositivo "saúde de mulheres lésbicas": (in) visibilidade e direitos. Revista Psicologia Política, São Paulo, v. 13, n. 26, p. 111-127, abr. 2013. Disponível em: <goo.gl/YhFtGc>. Acesso em: 21 dez. 2018.

CONSELHO FEDERAL DE PSICOLOGIA. Resolução $n^{0} 1$, de 29 de janeiro de 2018. Estabelece normas de atuação para as psicólogas e os psicólogos em relação às pessoas transexuais e travestis. Disponível em: <goo.gl/7r9r32>. Acesso em: 21 dez.

CONSELHO FEDERAL DE PSICOLOGIA. Despatologização das Identidades Trans e Travestis. Disponível em: < goo.gl/8FAP8L> Acesso em: 21 dez. 2018.

CORTINA, Adela. Cidadãos do mundo: para uma teoria da cidadania. São Paulo: Loyola, 2005.

CORTINA, Adela; MARTÍNEZ, Emilio. Ética. São Paulo: Loyola, 2005.

DINIZ, Débora; GUILHEM, Dirce. Bioética Feminista: o resgate político do conceito de vulnerabilidade. Revista Bioética, Brasília, v. 7, n. 2, 2009.

GARCIA, Cíntia L. et al. Saúde de Minorias Sexuais do Nordeste Brasileiro: Representações, Comportamentos e Obstáculos. Journal of 
Human Growth and Development, São Paulo, v. 26, n. 1, p. 94-100, 2016. Disponível em: <goo.gl/b48R31>. Acesso em: 21 dez. 2018.

GRACIA, Diego. Pensar a bioética: metas e desafios. 1. ed. São Paulo: Loyola, 2010.

JESUS, Jaqueline G. Orientações sobre identidade de gênero: conceitos e termos. 2. ed. Brasília, 2012. 42 p. Disponível em: < goo.gl/ LyoluJ>. Acesso em: $21 \mathrm{dez} .2018$.

JODELET, Denise. Representações sociais: um domínio em expansão. In: JODELET, Denise. Les représentations sociales. Paris: PUF, 1989. p. 31-61. Tradução: Tarso Bonilha Mazzotti. Revisão Técnica: Alda Judith Alves-Mazzotti. UFRJ- Faculdade de Educação, dez. 1993.[trocar qdo Marluce enviar]

LACERDA, Marcos; PEREIRA, Cícero; CAMINO, Leôncio. Um estudo sobre as formas de preconceito contra homossexuais na perspectiva das representações sociais. Psicologia: Reflexão e Crítica, Porto Alegre, v. 15, n. 1, p. 165178, 2002. Disponível em: <goo.gl/BpBN2B>. Acesso em: $21 \mathrm{dez} .2018$.

LIONÇO, Tatiana. Que direito à saúde para a população GLBT? Considerando direitos humanos, sexuais e reprodutivos em busca da integralidade e da equidade. Saúde e Sociedade, São Paulo, v. 17, n. 2, p. 11-21, 2008. Disponível em: <goo.gl/dR4HcY>. Acesso em: 21 dez. 2018.

MAKADON, Harvey J. Ending LGBT invisibility in health care: The first step in ensuring equitable care. Cleveland Clinic journal of medicine, Lyndhurst, v. 78, n. 4, p. 220-224, 2011.

MANSH, Matthew; GARCIA, Gabriel; LUNN, Mitchell R. From Patients to Providers: Changing the Culture in Medicine Toward Sexual and Gender Minorities. Academic Medicine, Phoenix, v. 90, n. 5, p. 574-580, 2015.

MARTINS, Eduardo S. T. et al. Psicanálise e homossexualidade: da apropriação à desapropriação médico-moral. Ide, São Paulo, v. 36, n.
57, p. 163-177, jun. 2014. Disponível em: < goo.gl/TA49Eg >. Acesso em: $21 \mathrm{dez} .2018$.

MELLO, Luiz et al. Políticas de saúde para lésbicas, gays, bissexuais, travestis e transexuais no Brasil: em busca de universalidade, integralidade e equidade. Sexualidad Salud y Sociedad, Rio de Janeiro, n. 9, p. 7-28, dez. 2011. Disponível em: <goo.gl/1nKvkd >. Acesso em: 21 dez. 2018.

MINAYO, Maria C. S. O desafio do conhecimento: pesquisa qualitativa em saúde. 11. ed. São Paulo: Hucitec, 2008.

MOREIRA, Michelle A.; GOMES, Anne J. M. Representações sociais de estudantes concluintes de enfermagem sobre transexualidade. Revista de enfermagem, Recife, v. 7, n. 6, p. 4.378-4.388, 2013. Disponível em: <goo.gl/jT7aWk>. Acesso em: 21 dez. 2018.

MOSCHETA, Murilo S.; FÉBOLE, Daniele S.; ANZOLIN Bárbara. Visibilidade seletiva: a influência da heterossexualidade compulsória nos cuidados em saúde de homens gays e mulheres lésbicas e bissexuais. Saúde \& Transformação Social, Florianópolis, v. 7, n. 3, p. 71-83, 2016. Disponível em: < goo.gl/rDb$\mathrm{Mjb}>$. Acesso em: $21 \mathrm{dez} .2018$.

MOSCOVICI, Serge. A representação social da psicanálise. Rio de Janeiro: Zahar, 1978.

MOSCOVICI, Serge. On social representation. In: FORGAS, Joe. (org.). Social Cognition. London: Academic Press, 1981. p. 181-209.

NELSON, James L. Still Quiet After All These Years Revisiting "The Silence of the Bioethicists". Journal of Bioethical Inquiry, Gewerbestrasse, v. 9, n. 3, p. 249-259, 2012.

PEREIRA, Cicero R. et al. O papel de representações sociais sobre a natureza da homossexualidade na oposição ao casamento civil e à adoção por famílias homoafetivas. Psicologia: Teoria e Pesquisa, Brasília, v. 29, n. 1, p. 79-89, 
mar. 2013. Disponível em: <goo.gl/qSHJ82>. Acesso em: 21 dez. 2018.

PEREIRA, Cícero R. et al. Preconceito contra homossexuais e representações sociais da homossexualidade em seminaristas católicos e evangélicos. Psicologia: Teoria e Pesquisa, Brasília, v. 27, n. 1, p. 73-82, mar. 2011. Disponível em: < goo.gl/VeNkWq>. Acesso em: 21 dez. 2018.

PINTO, Nuno; MOLEIRO, Carla. As experiências dos cuidados de saúde de pessoas transexuais em Portugal: perspectivas de profissionais de saúde e utentes. Psicologia, Lisboa, v. 26, n. 1, p. 129-151, 2012. Disponível em: < goo.gl/ zU7gZe>. Acesso em: 21 dez. 2018.

RODRIGUEZ, Ana M. M. Experiências de atenção à saúde e percepções das pessoas transgêenero, transexuais e travestis sobre os serviços públicos de saúde em Florianópolis/SC. 182 f. Dissertação (Mestrado em Saúde Coletiva)Universidade Federal de Santa Catarina, UFSC, Florianópolis, 2014.

SANTOS, Adelyany B.; SHIMIZU, Helena E.; MERCHAN-HAMANN, Edgar. Processo de formação das representações sociais sobre transexualidade dos profissionais de saúde: possíveis caminhos para superação do preconceito. Ciência e Saúde Coletiva, Rio de Janeiro, v. 19, n. 11, p. 4.545-4.554, nov. 2014. Disponível em: < goo.gl/Cz2vsD>. Acesso em: 21 dez. 2018.

SANTOS, Adilson R. et al. Implicações bioéticas no atendimento de saúde ao público LGBTT. Revista Bioética, Brasília, v. 23, n. 2, p. 400-408, ago. 2015. Disponível em: <goo. gl/tTEval>. Acesso em: 21 dez. 2018.

SCARDUA, Anderson; SOUZA FILHO, Edson A. O debate sobre a homossexualidade mediado por representações sociais: perspectivas homossexuais e heterossexuais. Psicologia: Reflexão e Crítica, Porto Alegre, v. 19, n. 3, p. 482-490, 2006. Disponível em: <goo.gl/ fwK8YW>. Acesso em: 21 dez. 2018.

SILVA, Ana L. R.; FINKLER, Mirelle; MORETTIPIRES, Rodrigo O. Vulneração e Iniquidades no atendimento à saúde de pessoas LGBT: uma abordagem sobre ética e reconhecimento. In: FIGUEIREDO, Glória L. A.; MARTINS, Carlos H. G.; AKERMAN, Marco (org.). Vulnerabilidades e saúde: grupos em cena por visibilidade no espaço urbano. São Paulo: Hucitec, 2018. p. 474-489.

SILVA, Ana L. R.; FINKLER, Mirelle. O movimento LGBT e a bioética crítica de inspiração feminista: convergências e potencialidades. Saúde \& Transformação Social, Florianópolis, v. 7, n. 3, p. 1-10, 2016. Disponível em: < goo. gl/NLcrRa>. Acesso em: 21 dez. 2018.

SNELGROVE, John W. et al. "Completely out-at-sea" with "two-gender medicine": A qualitative analysis of physician-side barriers to providing healthcare for transgender patients. BMC health services research, Medford, v. 12, n. 1, 2012. Disponível em: < goo. gl/MimCEB >. Acesso em: 21 dez. 2018.

SOUSA, Barbara C. et al. Famílias homoafetivas na Estratégia de Saúde da Família: uma reflexão bioética. Revista de Atenção à Saúde, São Caetano do Sul, v. 12, n. 39, p. 66-73, 2014. Disponível em: <goo.gl/VmlNrU>. Acesso em: 21 dez. 2018.

TESSER JÚNIOR, Zeno C.; KOVALESKI, Douglas F. A invisibilidade das pessoas LGBT na atenção à saúde. In: FIGUEIREDO, Glória L. A.; MARTINS, Carlos H. G., AKERMAN, Marco (org.). Vulnerabilidades e Saúde: grupos em cena por visibilidade no espaço urbano. São Paulo: Hucitec, 2018. p. 113-131.

WAHLERT, Lance; FIESTER, Autumn. A false sense of security: lesbian, gay, bisexual, and transgender (LGBT) surrogate health care decision-making rights. The Journal of the American Board of Family Medicine, Waltham, v. 26 , n. 6 , p. 802-804, nov. 2013.

WAHLERT, Lance; FIESTER, Autumn. Questioning Scrutiny: bioethics, sexuality, and gender identity. Journal of bioethical inquiry, Gewerbestrasse, v. 9, n. 3, p. 243-248, 2012. 